\title{
Competência regulatória da Presidência da República no setor brasileiro de telecomunicações: política regulatória, republicanismo e interesse público
}

Presidential Regulatory Competencies in the Brazilian Telecommunications Sector: Regulatory Policy, Republicanism and Public Interest Doctrine

\section{Resumo}

O presente estudo analisa a competência legal da Presidência da República para determinar o regime de prestação dos serviços de telecomunicações. Tendo em conta que a partição de competências atua como garantia institucional que preserva espaços de participação individual na formulação de políticas públicas, é feita a abordagem dos Planos Gerais de Outorga - PGO promulgados em 1998 e 2008. Para a apreensão de como a Presidência da República vem exercendo a sua competência legal, foi dado enfoque à participação desse órgão no processo de formulação dos PGOs e às aberturas institucionais que promovem participação política.

Palavras-chave: direito das telecomunicações; Poder Executivo; identidade do sujeito constitucional.

\section{Abstract}

This study examines the presidential competence to determine the legal regime for the provision of telecommunications services. The 1998 and 2008 General Delegations Plan - PGO are discussed given that the partition of competencies acts as an institutional guarantee that open up spaces for individual participation in the formulation of public policies. This analysis focuses on the role of the President of Brazil in the process of enacting PGOs and to the institutional gaps generated therewith for civic virtue.

Keywords: Telecommunications Law; Executive Power; Identity of the Constitutional Subject.

"Pesquisador do Grupo de Estudos em Direito de Recursos Naturais (GERN) integrante do Núcleo de Direito Setorial e Regulatório da Faculdade de Direito da Universidade de Brasília. Contato: 1ribeiro.cassio@gmail.com. 


\section{Apresentação do Problema}

A Lei Geral de Telecomunicações - LGT confere ao Poder Executivo a prerrogativa de, por meio de decreto, instituir ou eliminar a prestação de modalidade de serviço no regime público, concomitante ou não com a sua prestação no regime privado. Dado, de um lado, a associação das Tecnologias de Comunicação e Informação - TICs a garantias e liberdades constitucionais e, por outro, que a escolha do regime de prestação de determinada modalidade de serviço influi diretamente no seu nível de fruição pelos indivíduos, assume-se que essa competência, enquanto garantia republicana, deve ser exercida no sentido de realização de interesses públicos. Cumpre dizer: a caracterização do regime público como aquele que assegura a continuidade e a universalização da prestação de determinada modalidade de serviço essencial torna essa competência um importante instrumento de implementação de políticas públicas de telecomunicações.

O propósito do presente estudo é averiguar se o exercício concreto dessa competência regulatória se coaduna com esses postulados. Para isso, o trabalho vem assim estruturado: o segundo tópico cuida da revisão de literatura relevante, segmentando-as em literatura sobre a partição de competências regulatórias na LGT e sobre a relação entre a garantia institucional da separação dos poderes e o setor de telecomunicações; o terceiro tópico trata da teoria e do método subjacente, apresentando o conceito de identidade do sujeito constitucional, proposta por Michel Rosenfeld; o quarto tópico é a aplicação da teoria ao problema apresentado ou seja, é o momento de análise dos Planos Gerais de Outorga - PGOs promulgados pela Presidência da República; o quinto tópico, por fim, apresenta algumas das conclusões colhidas no trabalho.

\section{Revisão de Literatura}

Dentre os estudos em temas que tangenciam ou abordam frontalmente a questão da competência regulatória da Presidência da República no setor brasileiro de telecomunicações selecionamos quatro principais, que passamos a rever. 


\section{A. Literatura sobre Partição de Competências na LGT ${ }^{1}$}

A atribuição de prerrogativas regulatórias específicas ao Poder Executivo é um dos elementos que revela a ratio de partição de competências que o legislador ordinário conferiu à Lei Geral de Telecomunicações. Mais especificamente, cuida-se da relação entre a Presidência da República e a Agência Nacional de Telecomunicações Anatel no que se refere à competência desta última em elaborar e propor àquela a adoção das medidas que materializam as prerrogativas constantes dos incisos I a IV do art. $18^{2}$.

${ }^{1}$ Cuida-se aqui do estudo "Entre política e expertise: a repartição de competências entre o governo e a Anatel na Lei Geral de Telecomunicações", de Gustavo Binenbojm e André Rodrigues Cyrino, ambos da Universidade do Estado do Rio de Janeiro - UERJ.

${ }^{2}$ São elas as medidas de (I) instituir ou eliminar a prestação de modalidade de serviço no regime público, concomitantemente ou não com sua prestação no regime privado; (II) aprovar o plano geral de outorgas de serviço prestado no regime público; (III) aprovar o plano geral de metas para a progressiva universalização de serviço prestado no regime público; (IV) autorizar a participação de empresa brasileira em organizações ou consórcios intergovernamentais destinados ao provimento de meios ou à prestação de serviços de telecomunicações. Note-se que a redação do caput "Cabe ao Poder Executivo (...)" - não especifica que órgão do Poder Executivo concorrerá para o exercício dessas prerrogativas. Nesse sentido, poder-se-ia entender o Ministério das Comunicações como sendo também órgão exercente dessas competências listadas, e não apenas a Presidência da República. Acreditamos que, muito embora o Ministério das Comunicações possa ter (e efetivamente tem, como se verá adiante) participação no processo de elaboração dos atos referentes a essas competências, a Lei Geral de Telecomunicações deixa claro que o titular dessa competência é a Presidência da República, e não outro órgão executivo. Dois são os argumentos que sustentam essa tese. $\mathrm{O}$ primeiro e principal argumento refere-se à forma específica do ato que a parte final do caput do art. 18 elegeu para esse exercício - "(...), por meio de decreto:" -; e o segundo argumento refere-se à existência de outros dispositivos em que a Lei atribui ao "Poder Executivo" tarefas que não poderiam ser exercidos por outro órgão que não a Presidência: encaminhar mensagem ao Congresso Nacional (art. 11; 77 e 81, II); realizar despesas e investimentos necessários à instalação da Anatel (art. 16); levar em conta os interesses do País no cenário das relações internacionais (art. 18, parágrafo único); criar empresa estatal ou fundação (art. 190, parágrafo único). Os demais dispositivos em que "Poder Executivo" é empregado, mas sem referir-se necessariamente à Presidência da República revela que, ao longo da Lei Geral de Telecomunicações, a adoção do termo não é unívoco; mas não refuta a interpretação de que, nos

Revista de Direito, Estado e Telecomunicações, v. 4, n. 1, p. 173-196 (2012) 
A motivação subjacente a tal desenho institucional seria o de criar um sistema dinâmico de relação entre órgãos representativos e a Agência que fosse capaz de equalizar os imperativos de eficiência e legitimidade que informam a intervenção regulatória no setor. A autonomia da autarquia reguladora, por mais que lhe sirva como garantia de que sua legitimação poderá advir justamente da sua eficiência em fazer com que o setor efetivamente opere, limita-a, mas não a insula da política. ${ }^{3}$ As matérias que o legislador entendeu exibirem elevado teor político foram confiadas a órgãos que se submetem ao crivo democrático, tal como nas prerrogativas confiadas à Presidência.

Ademais, a eficiência, no Estado Democrático de Direito, é apenas um dentre outros vetores axiológicos que informam e legitimam a existência e funcionamento do Estado. Regulação extrapola expertise: é necessário instituir canais de comunicação entre agências reguladoras e poderes eleitos, sujeitando-as a controles ancilares pelo Executivo e pelo Legislativo. As agências devem representar, elas próprias, instrumentos de desenvolvimento, aperfeiçoamento da democracia e concretização de direitos fundamentais.

Perquirir, portanto, sobre a repartição de competência entre a Presidência da República e a Anatel na Lei Geral de Telecomunicações é realizar um

dispositivos citados, não se poderia referir, por exemplo, ao Ministério das Comunicações.

${ }^{3}$ Por razões que serão expostas adiante (cf. II.b), reputamos como falha a compreensão da autonomia conferida à agência reguladora como premissa institucional para assegurar um seu distanciamento da política e, com isso, promover a sua eficiência. Com uma certa historicidade, pode-se até compreender que a instituição de uma agência reguladora autônoma foi uma resposta ao aparelhamento político e ao subseqüente choque de gestão do sistema Telebrás, mas um estudo de viés constitucional do setor situa como oportuno o enfoque no papel que essa autonomia desempenha no processo de formulação das políticas públicas setoriais. Aqui, e ao contrário do que propõem Binenbojm e Cyrino, concebemos que ao ente regulador não foi conferida uma autonomia para eximir-se da política, mas sim uma autonomia para o exercício da política. Em outras palavras, também as agências reguladoras podem ser vistas como espaço de formulação de políticas públicas e postulação de interesses legítimos, como concebido por Aranha et al (2009, p.7).

Revista de Direito, Estado e Telecomunicações, v. 4, n. 1, p. 173-196 (2012)

DOI: https://doi.org/10.26512/1str.v4i1.21578 
estudo de caso entre política pública e regulação ${ }^{4}$. Estipular o sentido e alcance das prerrogativas regulatórias da Presidência da República importa como meio de determinar o procedimento jurídico para a atividade regulatória do Poder Executivo no setor brasileiro de telecomunicações. ARANHA (2005, p. 117-118) identifica nessa atribuição de regime jurídico público ou privado aos serviços de telecomunicações como necessário ao tratamento jurídico compatível com a dinamicidade dos serviços e a mobilidade da evolução social. É nesse sentido que a Lei Geral de Telecomunicações elege a essencialidade como critério para qualificação, pelo Presidente da República, do rol de atividades submetido a regime público. Esse critério está expresso no art. $65, \S 1^{\circ}$, segundo o qual caso determinada modalidade de serviço figurar na realidade social como essencial, perde-se a opção de política de governo do Presidente da República em submetê-la somente à prestação em regime privado. ${ }^{5}$

Propostos os critérios lógico-sistemático e teleológico para a interpretação dessas prerrogativas, é possível concluir $(a)$ pela vinculação da Anatel às políticas públicas do Legislativo e Executivo (in casu, o que inclui os decretos previstos no art. 18); (b) que o art. 19, III não junge o Executivo à Anatel em termos de iniciativa ou conteúdo; (c) a Presidência da República regula os incisos I a III do art. 18 independentemente de proposta da Anatel, mas tem o dever de apreciá-la, caso seja formulada; (d) a competência do art. 19, III não é privativa da Anatel; $(e)$ os decretos da Presidência da República previstos no art. 18 da LGT são dotados de

${ }^{4}$ Binenbojm e Cyrino (2008, p. 130) reconhecem a dificuldade de distinção entre essas duas instituições: "Com efeito, inexistindo uma distinção doutrinária autoevidente entre políticas públicas e regulação, cabe à lei traçar as fronteiras entre as diretrizes a serem definidas pelo governo (políticas públicas) e as decisões a cargo das agências (regulação)". Não se pode, de toda forma, olvidar o fato de que para além das fronteiras arbitradas pelo legislador ordinário, inexiste critério empiricamente aferível que permita distinguir política pública e regulação, tornando forçosa a conclusão de que a regulação é, ela própria, política pública. É a partir dessa indistinção que se fala, aqui, na propriedade do termo política regulatória como fenômeno que abrange, setorialmente, a tomada de decisões tanto dos órgãos representativos como também das agências.

${ }^{5}$ In verbis: "Não serão deixadas à exploração apenas em regime privado as modalidades de serviço de interesse coletivo que, sendo essenciais, estejam sujeitas a deveres de universalização" Lei Geral de Telecomunicações, art. 65, § $1^{\circ}$. 
conteúdo normativo e decisório, posto que expressões típicas do poder regulamentar do Executivo (art. 84, IV da Constituição Federal de 1988).

\section{B. Literatura sobre Separação de Poderes e Regulação de Telecomunicações ${ }^{6}$}

Passo seguinte no estudo sobre a partição de competências regulatórias na Lei Geral de Telecomunicações consiste em analisá-la sob o prisma não mais material da dicotomia entre eficiência e legitimidade, mas agora formal da separação de poderes.

Partindo dos conceitos de espaço regulatório (HANCHER e MORAN, 1989) ${ }^{7}$, e de regulação de resposta compreensiva (responsive regulation), (AYRES e BRAITHWAITE, 1992) ${ }^{8}$, chega-se à conclusão de que é também

${ }^{6}$ Cuida-se aqui de passagens das obras "Políticas Públicas Comparadas de Telecomunicações (Brasil-EUA)" (2005), tese de doutorado de Márcio Aranha; "Republicanismo, Instituições e a Ingestão de Normas Internacionais por Setores Regulados Brasileiros" (2011), e "A Separação de Poderes e o Processo de Institucionalização das Agências Reguladoras de Telecomunicações nos EUA e no Brasil" (2009), respectivamente dissertações de mestrado de Arthur Coimbra e Gabriel Laender, defendidas na Universidade de Brasília.

${ }^{7}$ Espaço regulatório é um construto analítico que se apresenta como alternativa à concepção reducionista de regulação como a oposição de interesses essencialmente públicos a agentes essencialmente privados, focando-se no espaço de interação entre os agentes como o locus de formulação de interesses. É oportuna a citação: "Em primeiro lugar, precisamente porque se trata de um espaço, ele pode ser ocupado. Em segundo lugar, porque se trata de um espaço, ele pode ser dividido desigualmente entre os atores: haverá, em outras palavras, participantes principais e secundários no processo regulatório. [...] Em quarto lugar, uma vez que 'espaço regulatório' é uma imagem usada para representar um conceito, ele pode ser aumentado por imagens similares: assim, dado que uma arena é um espaço delimitado, algumas vezes falamos de uma 'arena regulatória'. [...] Nesses termos, o espaço regulatório pode ser furiosamente disputado. Seus ocupantes estão envolvidos por vezes em lutas ferozes por vantagem. Qualquer investigação sobre o conceito envolve examinar o resultado de disputas competitivas, os recursos utilizados nessas disputas e a distribuição desses recursos entre as diferentes instituições envolvidas. Em outras palavras, o jogo de poder está no centro desse processo." HANCHER e MORAN, 1989, p. 277 apud LAENDER, 2009, p. 236.

${ }^{8}$ Enquanto a noção de espaço regulatório é proposta em alternativa à dicotomia entre público e privado, a ideia de uma regulação de resposta compreensiva busca superar a dicotomia estado-mercado, ou, mais especificamente, regulação-desregulação. Parte-se, aqui, do reconhecimento da interdependência entre a regulação privada e a

Revista de Direito, Estado e Telecomunicações, v. 4, n. 1, p. 173-196 (2012)

DOI: https://doi.org/10.26512/lstr.v4i1.21578 
ideológica a proeminência do Estado como agente regulador par excelence. Tal posicionamento privilegiado apenas se justifica na medida em que, em uma arena dominada por organizações, o Estado republicano é a forma institucional mediante a qual os indivíduos podem postular interesses sobre as pautas regulatórias. Emerge, aqui, a separação dos poderes como garantia institucional que preserva essa participação individual, justamente porque abriga a liberdade pública como valor central (LAENDER, 2009, p. 242).

Falar em separação de poderes em uma análise setorial ou regulatória, portanto, é falar na criação de ambientes institucionais em que o processo de formulação de políticas públicas seja permeável à participação dos indivíduos. É nesses termos que se pode compreender a criação da Agência Nacional de Telecomunicações como representativa de uma nova divisão dos poderes, por mais que, originalmente ao menos, não houvesse sido criada para a preservação de uma política pública de telecomunicações (LAENDER, 2009, p. 261). ${ }^{9}$ Isso porque, ao menos hoje, já é possível

estatal, o que permitiria identificar possibilidades interessantes abertas à mistura entre regulação pública e privada. A regulação de resposta compreensiva consistiria na estratégia regulatória que reconhece diferenciadas gradações e composições entre o público e o privado como resposta a contextos distintos. Assim, não se haveria de falar em maior ou menor regulação, mas em composições regulatórias distintas. Essa interdependência pode ser ilustrada pela seguinte citação: "Nossa visão é de que comunidade, mercado, estado e ordem associativa, cada uma é importante tanto para disputar, como para constituir o poder da outra. Em uma era de regulação em fluxo, todos os domínios de poder institucional são excepcionalmente vulneráveis. Sim, o poder regulatório do Estado é vulnerável à reafirmação desregulatória do mercado pelo empresariado. Mas o empresariado é também vulnerável à ordem associativa de sindicatos, grupos ambientalistas, e outros. E o Estado é vulnerável quando acusado de falha regulatória pela comunidade". AYRES e BRAITHWAITE, 1992, p. 14-15 apud LAENDER, 2009, p. 239.

${ }^{9} \mathrm{~A}$ federalização das políticas públicas para o setor de telecomunicações só foi possível na segunda metade do século passado, quando o governo militar implementou uma nova ordem institucional, liderada pela Embratel e Telebrás. Esses órgãos colonizaram o espaço regulatório e alçaram o Executivo federal à condição de formulador das políticas públicas em telecomunicações. Esse ambiente foi logo deturpado quando o comando das estatais passou a ser moeda no jogo de poderpolítico-partidário, causando a derrocada prematura do Sistema Telebrás. A ideia de uma agência reguladora surge, aqui, com o objetivo de preservar um ambiente 
reputar o caráter de garantias republicanas a determinadas conformações e procedimentos, de que são exemplo as consultas e audiências públicas realizadas por esse órgão regulador (OLIVEIRA, 2011, p. 204-207).

Avulta, nesse sentido, como ponto de análise a conformação do Conselho Consultivo da Agência Nacional de Telecomunicações ao seu propósito de atuar como o órgão de participação institucionalizada da sociedade na Agência (art. 33 da Lei Geral de Telecomunicações 9.472/97). Tratar-se-ia de instituir, também no órgão regulador, o reconhecimento da importância transversal do setor de Tecnologias da Informação e Comunicação - TICs. Daí a sua composição por representantes indicados pelo Senado Federal, pela Câmara dos Deputados, pelo Poder Executivo, pelas associações ou sindicatos empresariais do setor, por associações ou entidades defensoras dos direitos dos usuários e por entidades gerais da sociedade civil. A crítica que se faz é quanto à inserção de representatividade do Legislativo e do Executivo nesse Conselho, especialmente quando em virtude dos mecanismos institucionais republicanos de freios e contrapesos já existentes, parece prescindível a ocupação dessas vagas por esses poderes, posto que possuem eles já outros mecanismos, institucionais e não institucionais, de exercer influência sobre as decisões da Agência (OLIVEIRA, 2011, p. 208).

Também aqui se está a tratar da permeabilidade do setor a interesses legítimos que concorrem para a definição das suas políticas públicas. Os mecanismos institucionais republicanos de freios e contrapesos aparecem como garantia de que será difusa a produção das políticas de telecomunicações ${ }^{10}$ e, portanto, representa a ampliação do espaço regulatório para que dele se tornem agentes novos indivíduos e segmentos da sociedade civil. Essa sobreposição no Conselho Consultivo da Anatel, contudo, reforça, antes de qualquer outra coisa, a atuação da Presidência da

estável para a realização de investimentos externos no setor. LAENDER, 2009, p. 260-261.

${ }^{10} \mathrm{~A}$ produção difusa das políticas públicas desse setor está expressa na pluralidade de órgãos competentes para organizar a exploração dos serviços de telecomunicações, conforme se lê no enunciado do art. $1^{\circ}$ da Lei $n^{0}$ 9472/97: "Compete à União, por intermédio do órgão regulador e nos termos das políticas estabelecidas pelos Poderes Executivos e Legislativo, organizar a exploração dos serviços de telecomunicações".

Revista de Direito, Estado e Telecomunicações, v. 4, n. 1, p. 173-196 (2012)

DOI: https://doi.org/10.26512/lstr.v4i1.21578 
República no setor brasileiro de telecomunicações, tendência que vem expressa não apenas em um nível formal de conformação do Conselho Consultivo, mas principalmente em outras iniciativas de índole mais concreta. É o que se percebe da postura mais proativa do Poder Executivo no setor nos episódios do processo de execução do $2^{\circ}$ Plano Geral de Metas de Universalização, ou a coordenação do Programa Nacional de Banda Larga - PNBL e a reativação da Telebrás (OLIVEIRA, 2011, p. 202).

O descompasse surge quando a percepção do espaço regulatório como um espaço de postulação de interesses legítimos resta colonizado por ideais de bem-estar que contaminam a atuação das agências para fazer delas braços governamentais de qualidade de serviços e de satisfação dos consumidores. Esse é um empobrecimento conceitual que tolhe a abertura política para a participação direta cidadã (ARANHA, 2005, p. 198). Não por outra razão haveria a agência de ser autônoma senão enquanto resposta conceitual ao pressuposto de vigência de um espaço público, cuja presença somente pode ser sentida quando este não se confunde com os interesses de Governo. (ARANHA, 2005, p. 62). É nesse arranjo institucional, mais ou menos apto a facultar participação individual no processo de formulação das políticas públicas de telecomunicações, que se insere o exercício de competência regulatória pela Presidência da República no setor.

\section{Método e Teoria Subjacente}

O espaço de intervenção normativa que a Lei Geral de Telecomunicações reconhece ao poder Executivo é mais amplo que a determinação do regime jurídico em que será prestada determinada modalidade de serviço. Ao dispor sistematicamente sobre as competências do Poder Executivo, é estabelecido que

Art. 18. Cabe ao Poder Executivo, observadas as disposições desta Lei, por meio de decreto: I - instituir ou eliminar a prestação de modalidade de serviço no regime público, concomitantemente ou não com sua prestação no regime privado; II - aprovar o plano geral de outorgas de serviço prestado no regime público; III - aprovar o plano geral de metas para a progressiva universalização de serviço prestado no regime público; IV - autorizar a participação de empresa brasileira em organizações ou consórcios intergovernamentais 
destinados ao provimento de meios ou à prestação de serviços de telecomunicações.

Parágrafo único. O Poder Executivo, levando em conta os interesses do País no contexto de suas relações com os demais países, poderá estabelecer limites à participação estrangeira no capital de prestadora de serviços de telecomunicações. (Lei no 9.478/97)

Outras atribuições, esparsas na norma, são também conferidas a esse poder, como são exemplos a competência genérica de, ao lado do Legislativo, estabelecer as políticas de organização e exploração dos serviços de telecomunicações (art. $1^{\circ}$ ); fixar, por meio de decreto, a estrutura organizacional da Agência Nacional de Telecomunicações - Anatel (art. 10); indicar representantes ao Conselho Consultivo da Anatel (art. 34); reestruturar e promover a desestatização de diversas empresas controladas, diretamente ou indiretamente, pela União (art. 187); outorgar os serviços de radiodifusão sonora e de sons e imagens (art. 211); dentre outros.

É inegável que todos esses dispositivos tratam também de competências regulatórias da Presidência da República no setor de telecomunicações e, nesse sentido, também são parâmetros hábeis para aproximar a atuação setorial e regulatória desse órgão. A escolha do Plano Geral de Outorgas PGO como o objeto privilegiado de análise demanda, portanto, sua justificativa. É que aqui, de forma mais evidente e sensível que nas demais competências, o processo de elaboração e proposição dos decretos é capaz de revelar a forma segundo a qual o poder Executivo se apropria, ou mesmo deixa de se apropriar, de eventuais interesses públicos que motivariam alterações no regime de prestação de determinada modalidade de serviços de telecomunicações.

A premissa subjacente a essa afirmação é a de que, dado um arranjo setorial em que a partição de competências é compreendida como garantia institucional da participação política de indivíduos no processo de formulação de políticas públicas, ao menos no que diz respeito ao setor de telecomunicações, a competência que se reconhece a decretos presidenciais de modificar o regime jurídico de prestação de serviços está, já desde o seu início, finalisticamente vinculada. Cumpre dizer, não se deve perceber o PGO como um ato normativo que tem como remetente a Presidência da República e como destinatário toda a indústria de telecomunicações, por 
mais que aquela afirme ser uma autora que fala em nome de uma coletividade detentora de um determinado interesse público. O processo decisório que culmina na elaboração de um Plano Geral de Outorgas está, nesses termos, vocacionado a ser efetivo espaço de participação política.

HANCHER e MORAN (1989), ao proporem a superação da clássica dicotomia entre interesses privados que se reputam ao segmento industrial e interesses públicos que se reputam a todos os demais agentes setoriais (Governo, agência, sociedade, usuários) apontam para um espaço regulatório onde os diversos agentes disputariam a satisfação dos seus interesses (que não são essencialmente públicos e nem privados). Aqui, a noção de espaço regulatório é um construto analítico que informa ao poder Executivo a necessidade de não preterir ou privilegiar, a priori, interesses de determinados agentes. Nesse sentido, é preciso ter presente que, em se tratando do exercício dessa prerrogativa, o Executivo é tanto a instância com autoridade para conformar e compor as expectativas regulatórias, como também, ele próprio, um dos agentes interessados cujas expectativas devem ser conformadas e compostas na definição final dessa política pública. ${ }^{11}$

Nesses termos, o senso comum teórico dos juristas não pode se furtar da necessidade de que seja proposta a desconstrução desses remetentes e destinatários pré-definidos e em seu lugar seja postulada, em um primeiro momento, a mesma ausência que se propõe para a identidade do sujeito constitucional (ROSENFELD, 1995). ${ }^{12} \mathrm{~A}$ ideia de uma identidade do sujeito

${ }^{11}$ Falar em um interesse que é próprio do poder Executivo, em se tratando de políticas de telecomunicações ou em qualquer outra política, não é outra coisa senão assumir que essa instância representativa endossa também uma política de Governo que pode ser mais bem ou menos bem distinguida dos interesses que intenta representar.

12"Building upon this insight, I explore the thesis that it is ultimately preferable and more accurate to regard the constitutional subject as an absence rather than a presence. In other words, the very question of the constitutional subject is prompted because we find a lack in the place where we seek an ultimate source of legitimacy and authority for the constitutional order." (ROSENFELD, 1995, p. 1054) Mais adiante, Rosenfeld explicita que a identidade do sujeito constitucional deve ser tida como uma ausência em, ao menos, dois sentidos. Primeiro, no sentido de que não nega a sua indispensabilidade, necessitando de uma sua reconstrução, e; segundo, o sujeito constitucional sempre envolve a percepção de um "vazio" (lack) porque a incompletude lhe é inerente. 
constitucional vazia ou ausente é desenvolvida por Michel Rosenfeld a partir da teoria filosófica do sujeito de Georg Hegel e da teoria psicoanalítica do sujeito de Sigmund Freud e Jacques Lacan e é proposta como metodologia para solucionar os conflitos entre interpretações constitucionais que aparentam ser igualmente defensáveis. ${ }^{13}$

Essa postura desconstrutivista da identidade do sujeito constitucional é sucedida pelo momento de tomada de decisão. Isto é, o momento de definição do teor final da política pública de telecomunicações a partir da tentativa de composição dos diversos interesses legítimos que ali se empenhavam na luta pela prevalência no espaço regulatório. ${ }^{14}$ Ambos os

${ }^{13}$ Ainda que o pano de fundo de Rosenfeld seja o common law norte-americano ele não aposta na historicidade jurisprudencial (coerência) ou fática (integridade) para, de alguma forma, determinar a identidade do sujeito constitucional. Tudo que faz é afirmar de que lá um dos poucos pontos de consenso é o reconhecimento da Supreme Court como instância apta a determinar essa identidade. "At least in written constitutions, constitutional identity is bound to be problematic in terms of the constitution's relation to itself. A written constitutional text is inevitably incomplete and subject to multiple plausible interpretations. It is incomplete not only because it does not cover all subjects that it ought ideally to address, but also because it cannot exhaustively address all conceivable issues arising under the subjects that it does encompass. Moreover, precisely because of the incompleteness of the constitutional text, constitutions must remain open to interpretation; and that, in most cases, means open to conflicting interpretations that appear to be equally defensible. Thus, for example, one cannot get an adequate picture of the constitutional identity of the United States unless one supplements the constitutional text with the long string of interpretations and elaborations found in two centuries of Supreme Court decisions. Yet, the legitimacy of this larger picture has been vigorously contested as exemplified by one recent Attorney General's attempt to minimize the importance of Supreme Court decisions in shaping the country's constitutional identity, by placing a wedge between "the Constitution" and "constitutional law." But even the most exalted originalists, textualists, and purists have been unable or unwilling to flatly repudiate the Supreme Court's legacy in their attempts to cleanse constitutional identity of all its excesses and impurities." (ROSENFELD, 1995, p. 1050). Partindo da ideia de que tanto a garantia institucional da separação dos poderes quanto a ideia de uma identidade do sujeito constitucional ausente preservam espaços de participação política, resta como certo que ambos os construtos são igualmente aptos a redimensionar a percepção de remetentes e destinatários pré-determinados de políticas.

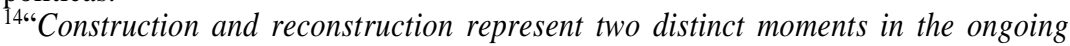
quest to obtain a better grasp of the evolving and incomplete self-identity of the constitutional subject. Constitutional decision making always arises under

Revista de Direito, Estado e Telecomunicações, v. 4, n. 1, p. 173-196 (2012)

DOI: https://doi.org/10.26512/lstr.v4i1.21578 
construtos analíticos, espaço regulatório e identidade do sujeito constitucional, importam por desnaturalizar a ideia de que as políticas públicas de telecomunicações são formuladas tendo como pré-determinados seus remetentes, detentores de interesses essencialmente públicos e seus destinatários, detentores de interesses essencialmente privados.

Dando um passo adiante, a afirmação de que subsiste um sujeito constitucional na política de definição do regime de prestação de determinadas modalidades de serviços de telecomunicações não pode ser feita sem se considerar a relação dessa política com a efetiva fruição de direitos e garantias fundamentais. Aqui reside, para as competências regulatórias do art. 18, incisos I e II da LGT, o parâmetro de análise, à luz da teoria apresentada, do exercício das prerrogativas regulatórias da Presidência da República no Setor Brasileiro de Telecomunicações. É o que passamos a fazer.

\section{A Presença do Sujeito Constitucional nas Políticas Setoriais: análise dos Planos Gerais de Outorga de 1998 e 2008}

O tópico anterior tratou de demonstrar como o exercício da prerrogativa regulatória do poder Executivo no setor brasileiro de telecomunicações está finalisticamente vinculado ao incremento da fruição de direitos e garantias fundamentais. Esse incremento, contudo, não se restringe à necessidade de que os serviços reputados pelo tecido social como essenciais passem a ser prestados em regime de direito público. É preciso que, para o próprio processo decisório, concorram as distintas expectativas sobre o que a política pública resultante deva vir a ser. São nesses termos, de preservação

conditions that preclude full determinacy, and makes construction necessary. In fact, constitutional decision making involves construction to the extent that constitutional issues always require making choices between two or more plausible alternatives. Thus, for example, the 1973 decision by the United States Supreme Court in Roe v. Wade, recognizing for the first time a constitutional right to abortion, certainly involved creative judicial construction. Indeed, neither the text of the Constitution nor previously articulated Supreme Court jurisprudence could fairly be taken to compel or preclude the decision reached by the Court. (ROSENFELD, 1995, p. 1065) 
de espaços de participação política, que falamos aqui na necessidade de ausência do sujeito constitucional.

Ao se analisar o histórico normativo do setor, logo se percebe que o êxito do poder Executivo federal em afirmar-se como esfera competente de regulação no setor, por volta da década de 70 , veio logo sucedido da busca de um Plano Nacional de Telecomunicações. Esse dado se torna mais que uma informação histórica quando se considera ser também o arranjo federalista como uma garantia institucional que preserva a possibilidade de participação política (em um âmbito de interesses mais bem localizado, ao menos). LAENDER (2009, p. 155-175) é quem retrata os antecedentes de criação de um sistema nacional federal, tendo uma narrativa que parte do extremo da descentralização federativa setorial, com a Constituição Republicana de 1891 e chega até o extremo da centralização federativa setorial, com a criação do Sistema Telebrás, por intermédio da Lei ${ }^{\circ}$ 5.792, de 11 de julho de $1972 .{ }^{15}$

Com a ineficiência na prestação de serviços sob o regime monopolista, bastante devido ao aparelhamento político e subseqüente crise de gestão do Sistema Telebrás promovida por Antônio Carlos Magalhães, é proposta a Emenda Constitucional $\mathrm{n}^{\circ}$ 8, de 15 de agosto de 1995, que introduziu no dispositivo constitucional do inciso XI do art. 21, a possibilidade de exploração "mediante autorização, concessão ou permissão" (RAMIRES, 2005, p. 21-22). A atual Lei Geral de Telecomunicações - LGT (Lei ${ }^{\circ}$ 9.472, de 16 de julho de 1997) é então promulgada para regular esse dispositivo constitucional.

Dado o contexto normativo, passemos aos Planos Gerais de Outorga.

\section{A. $1^{\circ}$ Plano Geral de Outorgas (Decreto no 2.534, de 2 de abril de 1998): instrumento de desestatização do Sistema Telebras}

De forma bastante singela, o primeiro Plano Geral de Outorgas estipulou que o "serviço telefônico fixo comutado destinado ao uso do público em

\footnotetext{
${ }^{15}$ Dos diversos episódios relatados, o mais emblemático para a atual conformação federalista das telecomunicações no país, por certo, foi a disputa havida entre o então presidente João Goulart e o governador do Estado da Guanabara, Carlos Lacerda, pelo controle da Companhia Telefônica Brasileira - CTB. Cf. Laender (2009, p. 164166).
} 
geral será prestado nos regimes público e privado" (art. $1^{\circ}$ ), sendo que a todos os demais serviços de telecomunicações foi dispensado o regime jurídico de direito privado (art. $3^{\circ}$ ). Sua vigência veio seguida e complementada pelo Plano Geral de Metas de Universalização do STFC Prestado em Regime Público (Decreto $n^{\circ}$ 2.592/1998), do Plano Geral de Metas de Qualidade para o STFC (Resolução Anatel no 30/1998).

$\mathrm{O}$ território brasileiro foi dividido em quatro áreas distintas para fins de exploração das modalidades do STFC (Anexo I), sendo três áreas relativas à prestação da modalidade local e mais uma área relativa à prestação das modalidades de longa distância nacional e internacional. A reestruturação do antigo sistema Telebrás foi feita pela sua habilitação a prestar as modalidades do STFC em regime público (art. $6^{\circ}$ ), sendo estimuladas as transferências de concessões ou de controle societário que contribuam para a compatibilização das áreas de atuação com essas regiões estipuladas no PGO, e para a unificação do controle societário das concessionárias atuantes em cada região $\left(\operatorname{art} .7^{\circ}\right){ }^{16}$

Ainda segundo o PGO, a desestatização implicará a imediata instauração de processo licitatório para a expedição, a um mesmo prestador e para cada região, de autorizações para exploração do serviço local e do serviço. (art. $9^{\circ}$, incisos $I$ e $\left.I I\right)$. Caso fosse uma concessionária, sua coligada, controlada ou controladora a obter a autorização, esta estaria obrigada a transferir o seu contrato de concessão a outrem em um prazo estipulado (art. $9^{\circ}, \S 3^{\circ}$ ). A limitação do número de prestadores a dois: uma concessionária (atuante, portanto, em regime de direito público) e uma autorizatária (atuante, portanto, em regime de direito privado), também chamada de empresaespelho, durou até 31 de dezembro de 2001 (art. 10), quando, então se passou a outorgar licença para prestação do STFC a todos interessados que reúnam os requisitos necessários.

16“No âmbito da telefonia fixa, houve a divisão do Sistema Telebrás em 3 grandes empresas regionais (TELE NORTE LESTE, TELE CENTRO SUL e TELESPE) e 1 empresa nacional (EMBRATEL). Àquelas caberiam os serviços locais e interurbanos intra-estaduais e interestadual dentro das respectivas áreas de concessão, enquanto à EMBRATEL caberia a exploração dos serviços intra-estaduais, interestaduais e internacionais em todo o território, gerando, assim, um potencial de competição com limites nos serviços intra-estaduais e interestaduais" (ARANHA, 2005, p. 102). 
Em outras palavras, o Plano Geral de Outorgas de 1998 estimula a reestruturação do antigo sistema Telebrás para que a cada região corresponda uma concessionária; passo contínuo, insere a competidora (empresa-espelho) autorizatária. A sucessora do sistema Telebrás beneficiava-se da rede instalada, da carteira de clientes e do fluxo de caixa já existente. A empresa espelho, enquanto autorizatária, não assumia os ônus que acompanhavam a prestação do serviço em regime de direito público (RAMIRES, 2005, p. 144-145).

Dessa forma, o poder Executivo se apropriou da sua competência regulatória no setor brasileiro de telecomunicações para instaurar um contexto de assimetria regulatória que fosse capaz de, de forma paulatina e concomitante, promover a desestatização da telefonia fixa comutada e estimular a competição no setor regulado. Por certo que essa especial composição de serviços prestados em regime de direito público e de direito privado ilustra bem o que AYRES e BRAITHWAITE (1992) conceituaram como regulação de resposta compreensiva, mas o que dizer quanto à participação no processo de formulação da política ou quanto ao incremento na fruição de direitos e garantias fundamentais? Que aberturas institucionais a Presidência da República efetivamente garantiu aos distintos interessados?

É importante destacar que o processo de elaboração do Plano Geral de Outorgas de 1998 esteve afastado da Presidência da República. Os trabalhos para a sua elaboração "foram iniciados pelo Ministério das Comunicações, tendo em vista que a instalação da Agência Nacional de Telecomunicações Anatel ocorreu apenas no início de novembro de 1997" ${ }^{17}$. Já em 1997, a Superintendência de Serviços Públicos da Anatel elaboram proposta do PGO, que foi submetida à consulta pública em 4 de dezembro de 1997. Na seqüência, o $1^{\circ}$ Plano Geral de Outorgas se torna o objeto de deliberação da Sessão Pública n 001 do Conselho Diretor da Anatel.

${ }^{17}$ Voto do Conselheiro Mário Leonel Neto, relator, na Sessão Pública ${ }^{\circ} 001$ do Conselho Diretor da Agência Nacional das Telecomunicações em 12 de fevereiro de 1998. Disponível pelo endereço http://www.anatel.gov.br/Portal/exibirPortalRedireciona.do?codigoDocumento=7607 , acesso em agosto de 2011.

Revista de Direito, Estado e Telecomunicações, v. 4, n. 1, p. 173-196 (2012)

DOI: https://doi.org/10.26512/lstr.v4i1.21578 
Sem que pese a efetividade da Consulta Pública promovida pela Anatel já nos seus primeiros meses de funcionamento ${ }^{18}$ ou mesmo a possibilidade de que a Agência tenha incorporado um discurso potencialmente atribuível ao poder Executivo ${ }^{19}$, cumpre registrar um fato. Na ocasião desse primeiro

${ }^{18}$ "Na consulta pública, foi fixado o prazo de 30 dias para que os interessados encaminhassem comentários e sugestões. A Agência recebeu, tempestivamente, contribuições das seguintes pessoas e entidades: Pedro Crosseti, Alejandra Herrera, Gilberto Gomes, Stelar Telecom, BSK Consultoria em Telecomunicações, Ercio Alberto Zilli, CRT - Companhia Riograndense de Telecomunicações, Telefônica do Brasil Holding S/A, Mario Dias Ripper, Kevin Louis Mundie, CTBC Telecom, BRTelecom, STET Internacional, Telecomunicações Brasileiras S/A - TELEBRÁS, Promon Eletrônica Ltda, MCI Communications Corporation, VICTORI Internacional. Houve também manifestações relacionadas ao teor da Consulta Pública, com o propósito de questionar a validade do ato emanado do Conselho Diretor. Considerando que não foram apresentadas sugestões específicas em relação ao texto publicado, tais manifestações foram tratadas pela Agência como expedientes normais, cujas respostas foram enviadas aos interessados. Todos os comentários e sugestões mereceram exame por parte do Conselho Diretor da Agência e a Superintendência de Serviços Públicos apresentou nova proposta de Plano Geral de Outorgas, incorporando as sugestões consideradas pertinentes." Excerto do voto do Conselheiro Mário Leonel Neto, relator, na Sessão Pública $n^{\circ} 001$ do Conselho Diretor da Agência Nacional das Telecomunicações em 12 de fevereiro de 1998. Disponível pelo endereço http://www.anatel.gov.br/Portal/exibirPortalRedireciona.do?codigoDocumento=7607 , acesso em agosto de 2011.

${ }^{19}$ São exemplos as falas do Conselheiro Presidente Renato Navarro Guerreiro, no sentido de que "o programa do atual governo brasileiro determinou a inserção do País, de forma efetiva, no grupo das nações que devem conduzir o processo de integração da sociedade através dos meios de comunicação, como exigência da nova era da informação" ou mesmo pronunciamentos que tomam para si preocupações tipicamente atribuíveis ao poder Executivo, como se percebe do pronunciamento do Conselheiro Antônio Carlos Valente da Silva, no sentido de que "as futuras concessionárias do Serviço Telefônico Fixo Comutado, mesmo que atuando em parte de determinada região, só poderão ultrapassar suas fronteiras, prestando serviço em outras regiões, quando todas as concessionárias da região, em conjunto, atingirem suas metas de universalização. Esta abordagem cria um incentivo adicional à antecipação do alcance destas metas de forma harmônica entre todas as áreas que compõem as regiões estabelecidas pelo Plano Geral de Outorgas, contribuindo para a redução das desigualdades regionais, que sabemos hoje ainda persistem, conduzindo a um melhor atendimento dos anseios da sociedade." Ambos os votos foram proferidos na Sessão Pública $n^{\circ} 001$ do Conselho Diretor da Agência Nacional das Telecomunicações em 12 de fevereiro de 1998. Disponível pelo endereço 
Plano Geral de Outorgas, a partilha de competências entre a Presidência da República e a Agência Nacional de Telecomunicações operou sem que aquela primeira houvesse representado um espaço de participação política.

\section{B. $2^{\circ}$ Plano Geral de Outorgas (Decreto $n^{\circ}$ 6.654, de 20 de novembro de 2008): instrumento de integração de redes e convergência digital}

O Plano Geral de Outorgas de 2008, que substitui o anterior, mantém a telefonia fixa comutada como o único serviço a ser prestado, concomitantemente, em regime de direito público e privado (art. $1^{\circ}$ ), atribuindo o regime jurídico de direito privado a todos os demais serviços de telecomunicações $\left(\operatorname{art.} 3^{\circ}\right.$ ). A principal distinção entre esse PGO e o seu antecessor é o seu permissivo a que transferências de concessão ou de controle de concessionária possa resultar em "Grupo que contenha concessionária em Setores de mais de uma Região" (art. $6^{\circ}, \S 1^{\circ}$ ). As excepcionalidades prosseguem, dispondo que determinados Municípios (art. $6^{\circ}, \S 5^{\circ}$ ) "não caracterizam critério" para os efeitos de "atuação obrigatória nas demais Regiões" (art. $6^{\circ}, \S 1^{\circ}$, inc. $I$ ) e nem para os efeitos de vedação das "transferências que resultem em Grupo que contenha concessionárias em Setores de mais de duas Regiões" (art. $6^{\circ}, \S 2^{\circ}$ ).

Essa abertura a uma potencial concentração de mercado, embora possa frustrar a resguarda de um ambiente de estímulo à concorrência que inspira a Lei Geral de Telecomunicações ${ }^{20}$, estariam condicionadas à observância do "maior benefício ao usuário" e "ao interesse social e econômico do País" (art. $6^{\circ}$ ). Essa passagem do PGO replica trecho do art. 84, $\S 1^{\circ}$, onde se lê que:

http://www.anatel.gov.br/Portal/exibirPortalRedireciona.do?codigoDocumento=7607 Acesso em agosto de 2011.

${ }^{20}$ Destaquem-se dois dispositivos: Art.84, $\S 1^{\circ}$. "As áreas de exploração, o número de prestadoras, os prazos de vigência das concessões e os prazos para admissão de novas prestadoras serão definidos considerando-se o ambiente de competição, observados o princípio do maior benefício ao usuário e o interesse social e econômico do País, de modo a propiciar a justa remuneração da prestadora do serviço no regime público". Art. $2^{\circ}$, inciso III "O Poder Público tem o dever de adotar medidas que promovam a competição e a diversidade dos serviços, incrementem sua oferta e propiciem padrões de qualidade compatíveis com a exigência dos usuários”. Grifos aditados.

Revista de Direito, Estado e Telecomunicações, v. 4, n. 1, p. 173-196 (2012)

DOI: https://doi.org/10.26512/1str.v4i1.21578 
Art. 84 (...) $\$ 1^{\circ}$ As áreas de exploração, 0 número de prestadoras, os prazos de vigência das concessões e os prazos para admissão de novas prestadoras serão definidos considerando-se 0 ambiente de competição, observados 0 princípio do maior benefício ao usuário e o interesse social e econômico do País, de modo a propiciar a justa remuneração da prestadora do serviço no regime público. (Lei no 9.478/97, grifos aditados)

Subjacente a esse artigo está a compreensão de que a resguarda da concorrência não é um valor per se, mas antes que apenas se justifica na medida em que não restringiria a possibilidade de que seja alcançado o maior benefício ao usuário e o interesse social e econômico do país. Em termos de normatização secundária, de toda forma, não deixa de ser evidente a drástica mudança de entendimento sobre a possibilidade de uma concessionária prestar ou não STFC em mais de uma das Regiões delimitadas nos Planos Gerais de Outorga ${ }^{21}$.

Apenas para exemplificar, a dimensão das mudanças levou a Frente dos Consumidores de Telecomunicações a apresentarem uma representação junto ao Ministério Público Federal contestando a legalidade da reforma e levantando suspeitas de improbidade administrativa contra a Anatel e o Ministério das Comunicações. A denúncia apresentada considerava a proposta de compra da Brasil Telecom pela Oi como o principal responsável pela aprovação do novo Plano Geral de Outorgas, o que infringiria o princípio da impessoalidade. ${ }^{22}$

${ }^{21}$ Basta que sejam contrapostos os artigos $7^{\circ}$ e 14 do PGO/1998 ao artigo $6^{\circ}$ do PGO 2008. "Só serão admitidas transferências de concessão ou de controle societário que contribuam para a compatibilização das áreas de atuação com as Regiões definidas neste Plano Geral de Outorgas e para a unificação do controle societário das concessionárias atuantes em cada Região" (art. 7, PGO/1998). E ainda, "a obtenção de concessão em determinada região por empresa já concessionária do serviço a que se refere 0 art. $1^{\circ}$ (STFC), sua coligada, controlada ou controladora implicará a obrigatória transferência a outrem, de contrato de concessão detido em outra Região (...)" (art. 14). No novo PGO: "as transferências que resultem em Grupo que contenha concessionárias em Setores de mais de uma Região definidas neste Plano Geral de Outorgas (...)" (art, 6º $\left.\$ 1^{\circ}, \mathrm{PGO} / 2008\right)$.

${ }^{22}$ Teletime News, Associação dos consumidores entram com representação contra 0 PGO, 4 de novembro de 2008. Disponível em: http://www.teletime.com.br/News.aspx?ID=101516,. 
O processo de formulação do novo $\mathrm{PGO}$, contudo, remonta a uma carta enviada pela ABRAFIX (Associação Brasileira de Concessionárias de Serviço de Telefone Fixo Comutado) à Anatel, solicitando remoção de restrições regulatórias "prejudiciais à integração de redes de serviços de telecomunicações e à plena convergência digital de voz, vídeo e dados". Nos documentos que sucedem, o poder público (in casu, Anatel e Ministério das Comunicações) fundamenta a proposta de alteração. ${ }^{23}$ Esquematicamente, fala-se em "adequar a organização dos serviços de telecomunicações no Brasil às novas tendências econômicas, tecnológicas e comportamentais que revestem a exploração dos serviços de telecomunicações" e em integrar redes multi-serviço (telefonia fixa, móvel e de serviços multimídia) com ampla abrangência territorial, como forma de promover melhores ofertas de serviços aos consumidores (economias de escala e escopo).

Da leitura dos documentos referidos, portanto, percebe-se que a abertura a possíveis concentrações de mercado é uma restrição ancilar, posto que constituiria estratégia do compartilhamento de infra-estruturas necessário à constituição de redes multi-serviços capazes de conferir maior benefício ao usuário. Em outras palavras, não afronta a Lei Geral de Telecomunicações, especialmente não afronta o disposto no art. $84, \S 1^{\circ}$. Em todo caso, diante do escopo proposto neste trabalho, cumpre indagar se a partição de competências representou, no que se refere ao PGO/2008, garantia institucional que preserva a Presidência da República como espaço de participação individual na formulação das políticas setoriais e em que medida pautou-se pela fruição de direitos e garantias individuais.

Aqui, tal como ocorrido no PGO/1998, o processo de elaboração da proposta teve como protagonistas a Agência Nacional de Telecomunicações e o Ministério das Comunicações. Foram esses órgãos, especialmente a Anatel, que representaram espaços institucionais de formulação das políticas

${ }^{23} \mathrm{O}$ poder público o faz por intermédio do Ofício 11/2008/MC, com exposição de motivos que encaminhou proposta de Consulta Pública para as alterações no PGO (http://www.telebrasil.org.br/impressao/artigos.asp?m=704) e na Consulta Pública $\mathrm{n}^{\circ} 23$ da Anatel (http://sistemas.anatel.gov.br/SACP/Contribuicoes/TextoConsulta.asp?CodProcesso $=\mathrm{C} 1175 \&$ Tipo $=1 \& O$ pcao $=$ andamento $)$, acessos em agosto de 2011 .

Revista de Direito, Estado e Telecomunicações, v. 4, n. 1, p. 173-196 (2012)

DOI: https://doi.org/10.26512/lstr.v4i1.21578 
expressas no PGO/2008. As oportunidades de manifestação sobre aquilo que mais aproximadamente se associaria à fruição de direitos e garantias institucionais (proposta de constituição de redes multi-serviços) ocorreram todas elas antes que a proposta do novo PGO chegasse à Presidência da República. Foram restritas à Consulta Pública ${ }^{0} 23$, de 16 de junho de $2008^{24}$, que a Anatel realizou e tratou de incorporar no texto aprovado pelo seu Conselho Diretor na sessão "de caráter de participação pública, aberta e ampla" do dia 16 de agosto de $2011^{25}$, em todo correspondente ao PGO promulgado pela Presidência da República, pouco mais de um mês depois.

\section{Conclusões e Pontos para Reflexão}

Como principal resultado da pesquisa, temos a comprovação de que os conceitos de "política regulatória", "republicanismo" e "interesse público" são variáveis jurídicas que podem ser aplicadas a setores regulados (no caso, telecomunicações) para que se lhe seja dimensionado quão mais permeável se revela um marco regulatório à concepção de uma identidade do sujeito constitucional ausente. A variável de "federalismo" originalmente proposta revelou-se inadequada a esse fim, dado que, por um processo de centralização aqui referido, muito pouco se confia hoje aos Estados federados em termos de competência regulatória.

A teoria subjacente ao estudo parte da compreensão de que a partilha de competências na Lei Geral de Telecomunicações, tanto quanto a própria separação de poderes, é a garantia institucional que preserva espaços de participação individual no processo de elaboração das políticas públicas setoriais. Sob essa perspectiva, foram analisados os Planos Gerais de

${ }^{24}$ Disponível pelo endereço, acessado em agosto de 2011, http://sistemas.anatel.gov.br/SACP/Contribuicoes/TextoConsulta.asp?CodProcesso= C1399\&Tipo $=1 \&$ Opcao $=$ realizadas

${ }^{25} \mathrm{~A}$ ata está disponível pelo endereço, acessado em agosto de 2011, http://www.anatel.gov.br/Portal/verificaDocumentos/documento.asp?numeroPublica cao $=226509 \&$ assuntoPublicacao $=$ ATA $\% 20 \mathrm{DA} \% 20$ SESS $\% \mathrm{C} 30 \% 20 \mathrm{~N} \% \mathrm{BA} \% 203 \%$ 20DO \%20CONSELHO\%20DIRETOR\%20DA\% 20ANATEL\%20-

$\% 2016 / 10 / 2008 \&$ caminhoRel=null\&filtro=1\&documentoPath=226509.pdf. 
Outorga de 1998 e 2008, de competência da Presidência da República, mas cuja propositura partiu da Agência Nacional das Telecomunicações.

A análise revelou que, em ambos os planos, houve o protagonismo da Agência Nacional de Telecomunicações (e também, em menor escala, do Ministério das Comunicações) no processo de elaboração das políticas. A Anatel, inclusive, foi a responsável pela promoção de audiências e consultas públicas para colher dos distintos interessados na formulação da política pública contribuições e expectativas que foram tidas em conta quando da elaboração da proposta final. Essas audiências e consultas públicas foram, ao lado de sessões do Conselho Diretor da Anatel e para ambos os Planos Gerais de Outorga, os únicos espaços institucionais facultados à participação individual.

Ainda que substanciais, poucas foram as modificações empreendidas pela Presidência da República nas redações aprovadas pelo Conselho Diretor da Anatel. Sem que se questione a efetividade dos espaços de participação individual criados pela Agência, é evidente que a sua abstenção em criar novo espaço de participação pública na definição dos regimes de prestação de serviços de telecomunicações. Resta mitigada a partição de competências enquanto potencial garantia institucional de preservação da participação no processo de formulação das políticas públicas de telecomunicações.

O outro parâmetro de análise foi, dada a associação das Tecnologias de Informação e Comunicação a direitos e garantias constitucionais, identificar, ao menos discursivamente, como se fundamentam ou motivam as propostas de Planos Gerais de Outorga. Foi possível identificar, relativamente a cada um dos decretos aqui analisados, uma motivação subjacente. O primeiro (PGO/1998) estava vinculado a uma engenhosa estratégia de desestatização do sistema Telebrás, enquanto o segundo (PGO/2008) estava vinculado a uma proposta de integração de redes e convergência digital. Embora eminentemente técnicas, essas motivações são facilmente associáveis a direitos e garantias constitucionais. Falar-se-ia em princípio da livre concorrência no primeiro caso e em serviço adequado ou direito à (efetiva) comunicação no segundo.

Em todo caso, mesmo aqui, a Presidência da República esteve aparentemente ausente da definição sobre os usos e práticas a que se prestariam os Planos Gerais de Outorga. Seria possível argumentar que esse Revista de Direito, Estado e Telecomunicações, v. 4, n. 1, p. 173-196 (2012) DOI: https://doi.org/10.26512/lstr.v4i1.21578 
órgão do Executivo tem seus interesses efetivamente atendidos por intermédio da nomeação de dirigentes ao Conselho Diretor da Anatel, mas então se questionaria quanto à efetiva autonomia política da Agência e dos riscos de seu aparelhamento e instrumentalização.

Em todos os lados, portanto, o que se observa, é um empobrecimento conceitual que tolhe a abertura política para a participação direta cidadã na Presidência da República, para tomar de empréstimo a expressão adotada por ARANHA (2005, p. 198), o que não significa, contudo, que a cúpula do Poder Executivo seja conivente com o processo de formulação das políticas públicas de telecomunicações. O Programa Nacional de Banda Larga PNBL e a Conferência Nacional de Telecomunicações - Confecom são duas das principais iniciativas que sinalizam para uma postura pró-ativa da Presidência nesse setor.

\section{Bibliografia}

ARANHA, M. I. (2005). Políticas Públicas Comparadas de Telecomunicações (Brasil-EUA). Brasília: Universidade de Brasília. Tese de Doutorado, Centro de Pesquisa e Pós-Graduação sobre as Américas CEPPAC.

et al (2009). Direito, Estado e Telecomunicações: dos primórdios ao novo modelo regulatório. In: Revista de Direito, Estado e Telecomunicações, v. 1, n. 1, p. 1-76. Brasília: Universidade de Brasília. AYRES, Ian e BRAITHWAITE, John (1992). Responsive Regulation: Transcending the deregulation debate. New York: Oxford University Press.

BINEMBOJM, Gustavo; CYRINO, André Rodrigues (2008). Entre política e expertise: a repartição de competências entre o governo e a Anatel na Lei Geral de Telecomunicações. In: Revista de Direito de Informática e Telecomunicações, v. 3, n. 4, jan. 2008.

HANCHER, Leigh e MORAN, Michael (1989). Capitalism, Culture and Economic Regulation. Oxford: Oxford University Press, p. 271-300.

LAENDER, Gabriel Boavista (2009). A Separação de Poderes e o Processo de Institucionalização das Agências Reguladoras de Telecomunicações nos EUA e no Brasil. Brasília: Universidade de Brasília. 273 p. 
Dissertação de Mestrado defendida no Programa de Pós-Graduação da Faculdade de Direito da Universidade de Brasília.

OLIVEIRA, Arthur Coimbra de (2011). Republicanismo, Instituições e a Ingestão de Normas Internacionais por Setores Regulados Brasileiros. Brasília: Universidade de Brasília. 244 p. Dissertação de Mestrado defendida no Programa de Pós-Graduação da Faculdade de Direito da Universidade de Brasília.

RAMIRES, Eduardo Augusto de Oliveira (2005). Direito das Telecomunicações: a regulação para a competição. Belo Horizonte: Fórum.

ROSENFELD, Michel. The identity of the constitutional subject. In:

Cardoso Law Review, New York: Yeshiva University Press, p. 1.0491.109, Janeiro de 1995. 